\section{Um olhar antropológico sobre a questão ambiental}

Por Michelle Gomes Lelis e José Ambrósio Ferreira Neto

Universidade Federal de Viçosa

(michelle.lelis@ufv.br; ambrosio@ufv.br)

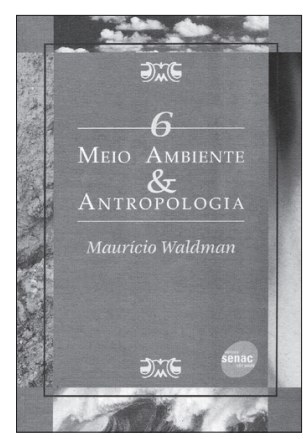

WALDMAN, Maurício.

Meio ambiente e antropologia. São Paulo: Editora SENAC, 2012. (Série Meio Ambiente, n. 6). 233 p. ISBN 85-7359-476-4

homem contemporâneo está em conflito permanente com o outro de si mesmo, visto como uma espécie de intruso alojado no seu interior, um 'invasor de corpo' preocupado em devorá-lo por dentro e, quem sabe, assumir de vez sua corporalidade (Waldman, 2012, p. 185).

Maurício Waldman, brasileiro, docente na Universidade de São Paulo (USP), onde leciona as disciplinas Administração dos recursos ambientais, Sociedade e meio ambiente, Ética profissional, Geografia da África negra e Introdução aos estudos africanos, é sociólogo, geógrafo e antropólogo pela USP. Possui Doutorado em Geografia Humana (2006) e Mestrado em Antropologia Social (1997), ambos pela USP. Com uma importante reflexão na área de antropologia social, escreveu "Meio ambiente e antropologia", entre outros livros. Neste texto, seu objetivo central foi discutir as relações que conjugam a antropologia com a questão ambiental. Paralelamente a essa preocupação, outra intenção foi alinhavar as possíveis contribuições do enfoque antropológico, no sentido de aprofundar a compreensão da temática relacionada ao meio ambiente.

$\mathrm{Na}$ introdução, esclarece que somente a partir das três últimas décadas do século passado é que a defesa da natureza passou a inspirar crescentes manifestações, envolvendo os mais diversos segmentos sociais ao redor do mundo. Tal mobilização, explicitamente posicionandose em favor de uma relação equilibrada com o meio ambiente, configurou-se por intermédio de um rol de reivindicações impensáveis, mesmo em passado histórico não muito distante. É nesse contexto que o autor justifica a importância da análise do meio ambiente, um tema contemporâneo e urgente de mudanças.

Como foco da sua reflexão, ele ressalta que a antropologia tem se voltado, cada vez mais abertamente, para o estudo dos processos sociais e culturais na sua acepção mais ampla, independentemente da localização no espaço ou no tempo. Na antropologia, a cultura distingue um modo de vida típico de um grupo de pessoas, fundamentado em comportamentos apreendidos e transmitidos de geração a geração, por meio da língua e do convívio social.

O primeiro capítulo do livro explana sobre a relação entre "Antropologia, questão ambiental e cultura", trazendo algumas considerações relacionadas com as potencialidades da antropologia enquanto ciência da cultura. Waldman detalha o debate a respeito das possíveis contribuições da antropologia e sua particularidade diante das demais disciplinas. Para o autor, tanto a biologia quanto a geografia desconsideram a abordagem social e cultural, não as utilizando para analisar a questão ambiental.

O autor evidencia a proeminência dos estudos clássicos desenvolvidos no âmbito da antropologia relativamente às potencialidades da disciplina para o entendimento da questão ambiental. Ele aponta que uma grande produção teórica efetivou-se em termos do paradigma da oposição entre cultura e natureza, atentando para a postura do antropólogo.

LELIS, Michelle Gomes; FERREIRA NETO, José Ambrósio. Resenha: Um olhar antropológico sobre a questão ambiental. Boletim do Museu Paraense Emílio Goeldi. Ciências Humanas, v. 9, n. 2, p. 569-571, maio-ago. 2014. DOI: http://dx.doi.org/10.1590/1981-81222014000200017.

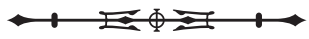


No segundo capítulo, denominado "Cultura, mundo tradicional e meio ambiente", a análise centra-se no homem tradicional e nas implicações do seu relacionamento com o meio natural. $\bigcirc$ autor deixa claro que, qualquer que seja o tipo de relacionamento estabelecido pela sociedade tradicional com o meio natural, este, no geral, mantém seus grandes ciclos em funcionamento. Ao contrário da sociedade contemporânea, o mundo da tradição pautou-se por uma convivência com a esfera do natural, e não pela sua exclusão.

No terceiro capítulo, "Temporalidade, modernidade e natureza”, visando sublinhar o que há de descontínuo nas duas grandes esferas da cultura humana que define como objeto da discussão - quais sejam, o mundo da tradição e o da modernidade -, o autor analisa as mudanças que o mundo contemporâneo instaurou na forma de compreensão do meio natural, assim como no relacionamento mantido com este. Isso sem perder de vista o mundo tradicional, cujo estranhamento conduz a se colocar em questão o que aparenta ser autenticamente novo.

Ele destaca que o tempo linear e progressivo, emanação de forças sociais que subentendiam os humanos e a natureza como elementos à disposição do progresso, excluiu todas as acepções sensíveis porventura existentes. Por isso mesmo, o homem contemporâneo está em conflito permanente com o outro de si mesmo, visto como uma espécie de intruso alojado no seu interior, um "invasor de corpo", preocupado em devorá-lo por dentro e, quem sabe, assumir de vez sua corporalidade. Separado física e psiquicamente dos seus semelhantes, fica comprometido para o homem moderno qualquer vínculo duradouro e sincero do indivíduo com o coletivo e com o espaço público.

Até o quarto capítulo, "Antropologia, humanidade e questão ambiental", o autor percorre um caminho que conduz o leitor desde os tempos mais remotos até as cintilantes metrópoles da modernidade. Nesse momento, Maurício Waldman traça alternativas, propõe enfoques e costura proposições referentes ao tema primordial. Conclui, nesta parte, que a diversidade cultural não pode estar dissociada da diversidade biológica, sendo redobrado o interesse pela perpetuação dos estilos de vida que se mantiveram regrados pela tradição.

A partir da análise construída por Waldman, ressaltase que o conceito de cultura, além de materializar-se como um instrumental de indispensável importância para a análise das sociedades tradicionais, mantém, de igual modo, seu vigor operatório e sua eficácia na avaliação do dinamismo cultural contemporâneo. A cultura perpassa por todo um rol de comportamentos relacionados com o meio ambiente e, na ausência dessa perspectiva, necessariamente qualquer avaliação estaria prejudicada na sua fundamentação, nas suas propostas e nas suas conclusões.

$\mathrm{Na}$ "Conclusão", o autor ressalta que o esforço de sua análise foi muito mais direcionado para construir uma perspectiva de avaliação, ao invés de pensar sobre formas de gestão, atividades gerais ou aplicadas da disciplina. Por outro lado, argumenta que essa opção em nada seria impeditiva da indicação de problemáticas com as quais a antropologia pode, com toda distinção possível, prontificar-se a destinar sua contribuição no que se refere à questão ambiental.

Para tanto, ao longo do texto, Waldman dialoga com diversos autores, entre eles François Laplantine (1988), "Aprender antropologia", Edward Evans-Pritchard (1978), "Os Nuer: uma descrição do modo de subsistência e das instituições de um povo nilota”, e Walter Neves (1996), "Antropologia ecológica: um olhar materialista sobre as sociedades humanas", para argumentar e refletir sobre a relação da antropologia com o meio ambiente. Ele apresenta uma abordagem educativa interdisciplinar por meio de duas áreas, meio ambiente e antropologia, transformando-as em uma antropologia ambiental, empenhada em revelar o caráter transformador do homem em sociedade diante do ambiente natural, instigado particularmente pela dimensão da cultura, da sociedade e das suas dinâmicas.

A antropologia, tendo por objetivo estudar a mais vasta gama possível da diversidade humana nos modos de vida, nas formas de organização social, nos

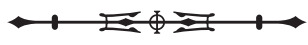


comportamentos e nas crenças, foi levada a privilegiar a observação das sociedades que permanecem (ou que permaneceram) fora do quadro unificador, representado pela civilização técnica e científica corporificada no Ocidente moderno. Dessa forma, estudos antropológicos privilegiam permanentemente a periferia do sistema dominante.

Segundo o autor, é justamente nos marcos da modernidade que os problemas ecológicos se especificaram na sua plenitude. Dessa forma, esclarecer e discutir as perspectivas da antropologia, enquanto disciplina, para com este mesmo mundo moderno abre caminhos para evidenciar o alcance das possíveis contribuições, assim como da eficácia operacional das abordagens que agitam o interior do seu campo teórico.

A capacitação da antropologia em identificar opções diversas das que regram o mundo moderno pode, de igual modo, prontificar-se para consolidar propostas alternativas aos desafios criados ao longo do processo de expansão da civilização ocidental, entre esses evidentemente os de ordem ambiental.

Waldman discute os conceitos de cultura e de natureza, além de reforçar a importância da diferença entre etnografia e etnologia. Afirma que a antropologia cultural teve sua consolidação enormemente apoiada no paradigma da oposição entre cultura e natureza.

Outro argumento do autor é que o leque de consequências da modernidade possui rebatimentos inquestionáveis no relacionamento com o meio natural. Basicamente em razão de que, com a modernidade, o fruir do tempo se materializa a partir de uma sobreposição globalmente desarmoniosa para com o tempo da natureza, o dos homens e com todos os demais tempos sociais, entendidos como obstáculos à implantação dos ritmos e das sequências da temporalidade moderna.
Outor destaca que o conceito de meio ambiente diz respeito aos elementos habilitados a influenciarem o dinamismo social, a repercussão das intervenções culturais e o conjunto das condições que permitem o estabelecimento e a reprodução da vida humana. Assim, ele propõe a construção de uma antropologia ambiental, preocupada em identificar os vínculos indissociáveis que a crise do meio ambiente sustenta com o padrão civilizatório, que é origem da sua manifestação. Tanto no passado do homem quanto nos dias de hoje, a questão ambiental relaciona-se sumamente com um sistema de poder econômico, social, político e ideológico, não podendo ser aquilatada na sua devida extensão na ausência desses referenciais.

Este ensaio, ao mesmo tempo desafiador e aberto aos questionamentos, apresenta a importância de abordar diálogos entre duas áreas abrangentes, como meio ambiente e antropologia, reforçando a possibilidade e a necessidade do trabalho interdisciplinar, com o intuito de minimizar os problemas ambientais causados pelo homem. $O$ autor manifesta nas entrelinhas sua esperança e expectativas de que a humanidade consiga construir um oikos comum a todas as pessoas, um mundo socialmente justo e ecologicamente responsável, no qual o homem não mais permaneça artificialmente dividido e encontre-se na sua totalidade.

\section{REFERÊNCIAS}

EVANS-PRITCHARD, Edward E. Os Nuer: uma descrição do modo de subsistência e das instituições de um povo nilota. São Paulo: Perspectiva, 1978. (Coleção Estudos, n. 53).

LAPLANTINE, François. Aprender antropologia. São Paulo: Brasiliense, 1988.

NEVES, Walter. Antropologia ecológica: um olhar materialista sobre as sociedades humanas. São Paulo: Cortez, 1996. (Coleção Questões da Nossa Época, v. 59). 
